ORIGINAL ARTICLE

\title{
Outcome of dynamic hip screw with trochanteric stabilizing plate in treatment of unstable intertrochanteric femoral fractures in elderly patients.
}

\author{
Muhammad Asif ${ }^{1}$, Yaqoob ur Rehman², Sardar Sohail Afsar ${ }^{3}$
}

Article Citation: Asif M, Yaqoob ur Rehman, Afsar SS. Outcome of dynamic hip screw with trochanteric stabilizing plate in treatment of unstable intertrochanteric femoral fractures in elderly patients. Professional Med J 2022; 29(1):31-35. https://doi.org/10.29309/TPMJ/2022.29.01.3433

\begin{abstract}
Objective: To know about the outcome of dynamic hip screw with trochanteric stabilizing plate in treatment of unstable inter-trochanteric femoral fractures in elderly patients. Study Design: Descriptive study. Setting: Maqsood Medical Complex, Pak Medical Centre and Habib Medical Complex. Period: August 2016 to July 2018. Material \& Methods: Total of 70 patients with unstable inter-trochanteric fracture and age above 60 years were included in the study. The fracture was fixed with dynamic hip screw and trochanteric stabilizing plate. Patients were evaluated every month after surgery for healing of fracture. Final functional outcome was measured at 6 months after surgery with Harris Hip Score. Results: Out of 70 patients $44(63 \%)$ were females and $26(37 \%)$ were males. Mean age was $74.34(S D+08.31)$ years with range of 60 to 87 years. Mean Harris Hip Score at 6 months was $85 \%$ with standard deviation of \pm 4.Ten $(14 \%)$ patients had excellent, $40(58 \%)$ patients had good, $16(23 \%)$ patients fair and $4(5 \%)$ patients poor functional outcome. Conclusion: Excellent and good functional outcome can be achieved in unstable inter-trochanteric fractures fixed with dynamic hip screw and trochanteric stabilizing plate in majority of patients.
\end{abstract}

Key words: $\quad$ Dynamic Hip Screw, Trochanteric Stabilizing Plate, Unstable Inter-Trochanteric Femoral Fracture.

\section{INTRODUCTION}

Inter-trochanteric fractures are one of the most common fractures in the human body. ${ }^{1}$ Most fractures occur in people older than 60 years of age mostly caused by low energy trauma that is a fall while walking. These are frail patients with multiple medical co-morbidities and suffer from higher mortality in post-operative period. ${ }^{2}$ Elderly people are susceptible to hip fractures due to osteoporosis and most of these patients are female in post-menopausal period. ${ }^{3}$ Surgery is mainstay of treatment to regain mobility as soon as possible. Failed internal fixation carries a poor prognosis and leads to an increase in the length of hospital stay and healthcare costs. ${ }^{4}$ Stable surgical fixation is of paramount importance to walk on feet again. ${ }^{16}$

Dynamic hip screw has been the mainstay of treatment for fixation of intertrochanteric fractures since its introduction in the 1970s. ${ }^{17}$ However it have been observed that intertrochanteric fractures with unstable configurations such as $\mathrm{AO}$ (Arbeitsgemeinschaft für Osteosynthesefragen) type A2 or A3 fractures or fractures with broken lateral wall of greater trochanter treated with dynamic hip screw (DHS) alone results in various complications such as medial translation of the femoral shaft and lateralization of the proximal femoral fragment with neck shortening, varus collapse of neck and screw cutout and finally poor functional outcome. ${ }^{5}$ This is because dynamic hip screw requires intact lateral wall of greater trochanter for stability. When lateral wall of greater trochanter is broken then some form of lateral reconstruction is required and this is done with trochanteric stabilizing plate. It is applied over dynamic hip screw. Trochanteric stabilizing plate (TSP) in these cases provides a support or buttress to broken lateral wall of greater trochanter

1. FCPS (Ortho), Consultant Orthopedic Surgeon, Maqsood Medical Complex, Peshawar.

2. FCPS, Assistant Professor Orthopedic Surgeon, Noshera Medical College / Pak Medical Centre, Peshawar.

3. FCPS, Associate Professor Orthopedic, Nowshera Medical College \& Qazi Hussain Ahmed Medical Complex, Nowshera. 
and prevents aforementioned complications improving functional outcome. ${ }^{6,7}$

Alternative options for treatment of unstable intertrochanteric fractures are Gamma nail or proximal femoral nail; however they are responsible for some complications which are not encountered with dynamic hip screw. $8,9,10$ These implants are more costly and many surgeons are not well acquainted with their application. Use of trochanteric stabilizing plate not only extends the indications for dynamic hip screw for unstable inter-trochanteric fractures but also prevents some of the complications associated with newer implants such as Gamma nails. ${ }^{18}$

The aim of the study is to evaluate the results of dynamic hip screw with trochanteric stabilization plate for management of unstable intertrochanteric fracture in our setup as very few studies are available on this.

\section{MATERIAL \& METHODS}

This was a descriptive case series study in which 70 consecutive patients with age 60 years and above of both genders with unstable inter-trochanteric fractures defined as a fracture running between or through both trochanters i.e. greater and lesser trochanter with loss of intactness of posteromedial cortex were included in the study. Sample size was calculated using prevalence of $0.28 \%{ }^{20}$, 95\% level of confidence and 95\% confidence interval. Study was conducted in different private hospitals of Peshawar namely Maqsood Medical Complex, Pak Medical Centre and Habib Medical complex from $1^{\text {st }}$ August 2016 to $31^{\text {st }}$ July 2018. All admissions were done through accident and emergency department. Written consent from patients was taken and as this study was conducted in different private set ups so there was no governing body for approval from Ethical Review Board (550/IERB/NMC). Diagnosis was made with conventional radiographs in anteroposterior and lateral views and fractures were classified with AO (Arbeitsgemenschaft fur Osteosynthesefragen) classification system. AO type 31A2 and $31 \mathrm{~A} 3^{19}$ were included in the study because they are considered unstable. After admission patients were evaluated for surgical fitness and consent was obtained. If patient was found physiologically stable then surgery was performed as soon as possible otherwise they were operated on the next available elective list after more thorough evaluation.

Patients with this fracture having pre injury hip Harris score in excellent grading were included in this study. Exclusion criteria was patient unfit for surgery, non-ambulatory pre-injury status, hip Harris score falling below excellent grade, already operated limb and pathological fractures.

Surgery was performed on fracture table and fracture reduced closely under image intensifier. Internal fixation was then be performed using 4 to 6 hole dynamic hip screw (DHS) plate with $135^{\circ}$ angle and appropriate sized lag screw. Trochanteric stabilizing plate (TSP) was then applied over the dynamic hip screw (DHS) and fixed in place with bicortical screws. All procedures were performed by a single senior orthopaedic surgeon. Implants were provided by a single manufacturer The Esmico International. To check quality of osteosynthesis X-ray were obtained on first postoperative day. To prevent infection all patients received Inj. Cefuroxime $1.5 \mathrm{~g}$ IV stat at induction of anesthesia and then thrice daily for 2 additional days. To prevent DVT patients received Inj. Enoxaprine 40mg S/C OD for 7 days postoperatively. Postoperatively patients were mobilized as soon as tolerated on crutches allowing toe touch to the ground on affected side and then full weight bearing when union was achieved typically at 8 to 10 months. Patients were followed in OPD every month for 6 months. At each visit fracture was evaluated radiologically with $\mathrm{x}$-rays to check the progress of healing.

Data was collected on a structured proforma and was analyzed using SPSS version 16. Functional outcome was measured at the end of 6 month duration of follow up using Harris Hip Score $\mathrm{S}^{20}$ and was excellent in $14 \%$, good in $58 \%$, fair in $23 \%$ and poor in $5 \%$.

\section{RESULTS}

Out of 70 patients 44 (63\%) were females and 
$26(37 \%)$ were males. Mean age was 74.34(SD +08.31 ) years with range of 60 to 87 years. 40 (58\%) patients had $\mathrm{AO}$ type $31 \mathrm{~A} 3$ fracture while remaining $30(42 \%)$ had $A O$ type $31 \mathrm{~A} 2$ fracture. Mean Harris Hip Score at 6 months was $85 \%$ with standard deviation of $\pm 4.10(14 \%)$ patients had excellent, $40(58 \%)$ patients had good, 16 (23\%) patients fair and $4(5 \%)$ patients poor functional outcome. Average time to union was 14 weeks (13-20 weeks). Two patients (2.8\%) developed deep surgical site infection with purulent discharge from wound who underwent debridement of wound with implant retention. $\mathrm{He}$ responded eventually to prolonged intravenous and oral antibiotic course and had fracture union achieved at 9 months. Two patients $(2.8 \%)$ with AO type $31 \mathrm{~A} 3$ fracture developed screw cut out and implant failure and was treated with total hip arthroplasty. Average limb shortening was $9 \mathrm{~mm}$ with six patients (8.57\%) whose shortening exceeded $20 \mathrm{~mm}$. Shortening was due to union being achieved in relatively varus neck shaft angle and fracture impaction and was more common in comminuted fractures.

\begin{tabular}{|c|c|l|}
\hline Functional Outcome & Frequency & Percentage \\
\hline Excellent & 10 & $14 \%$ \\
\hline Good & 40 & $58 \%$ \\
\hline Fair & 16 & $23 \%$ \\
\hline Poor & 4 & $5 \%$ \\
\hline Total & 70 & $100 \%$ \\
\hline Table-l. Stratification of functional outcome into \\
groups.
\end{tabular}

Mean Harris Hip Score was 85 with standard deviation of \pm 4 SD.

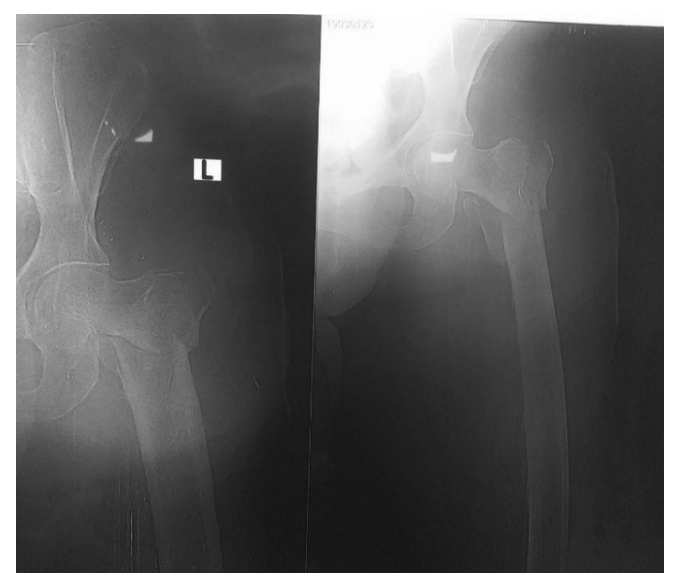

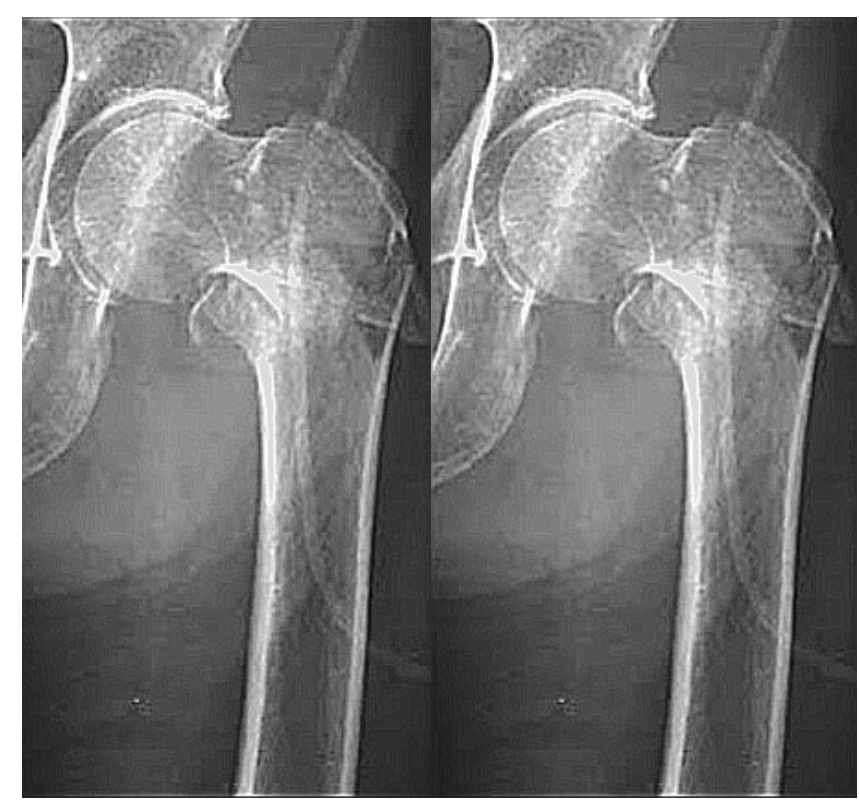

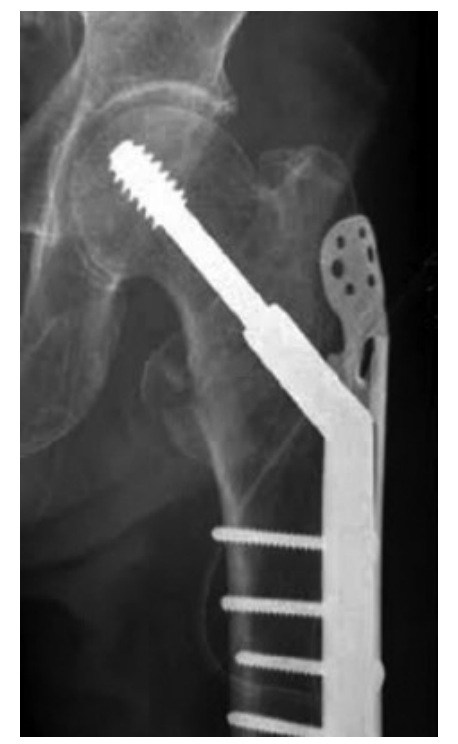

\section{DISCUSSION}

Our study showed Mean Harris Hip Score of 85\% could be achieved in unstable intertrochanteric fractures treated with trochanteric stabilizing plate mounted over dynamic hip screw. $72 \%$ of the patients in our study achieved excellent or good functional outcome.

Similar results were found in a study conducted by T. Nizegorodcew et.al in which $130(60 \%)$ patients were females and 85 (40\%) were males. Average healing time was 7.2 weeks. Mean Harris Hip Score was 79.7 with $56 \%$ of excellent result, $29 \%$ good, $18 \%$ fair and $13 \%$ poor result. There were 2 cases of limb shortening more than $2 \mathrm{~cm}$ 
and 9 cases of pain due to trochanteric plate. Generally low rate of complications was observed with use of trochanteric stabilizing plate. ${ }^{11,15}$

Gupta et.al did a study in which 74 patient with trochanteric fractures were treated with dynamic hip screw and trochanteric stabilizing plate. There were 34 males and 40 female patients. Average age was 72 years. Union was achieved in average of 13 weeks. No limb shortening was observed in any of the cases except six patients who had less than anatomical reduction. Functional outcome evaluated using Salvati Wilson score showed greater than 30 points (out of 40) in 55 patients and greater than 20 points in remaining 19 patients. $^{6}$

Babst $R$ et.al did a study in which 39 patients with unstable inter-trochanteric fractures were treated with dynamic hip screw and trochanteric stabilizing plate. Lateralization of the greater trochanter was successfully prevented in all fractures. Mean limb shortening was 5.37 millimeters. Four patients suffered limb shortening exceeding fifteen millimeters. Functional results were excellent and good in 87 percent of patients and fair in 13 percent according to the Salvati-Wilson score. In unstable pertrochanteric fractures with small or missing lateral cortical buttress, the addition of a TSP to the DHS effectively supports the unstable greater trochanter fragment and can prevent rotation of the head-neck fragment. Excessive fracture impaction and consecutive limb shortening was prevented by this additional implant in 90 percent of these patients. ${ }^{12,14}$

Similar results were obtained in a study conducted by Bhatti $A$ et.al in which 45 elderly patients above the age of 60 years with unstable inter-trochanteric fractures were treated with trochanteric stabilizing plate and dynamic hip screw. Lateralization of greater trochanter with resultant medialization of the femoral shaft was successfully prevented in 34 (75.55\%) fractures. The average leg length discrepancy was $15.5 \mathrm{~mm}$. The $28(62.66 \%)$ patient achieved excellent to good score on Salvati-Wilson Functional score, $11(24.44 \%)$ fair and 6 (13.33\%) patients achieved poor score. ${ }^{13}$
This study helped finding a method which is familiar to most of the surgeon and is affordable economically for our population. Also there is no local study present so it will pave way for further research.

The limitations of the study was that it is a descriptive study. Hopefully further comparative studies will be carried out.

\section{CONCLUSION}

Excellent and good functional outcome can be achieved in unstable inter-trochanteric fractures fixed with dynamic hip screw and trochanteric stabilizing plate with very few complications. However long term prospective comparative study is recommended to augment our findings.

Copyright $(13$ Sep, 2021.

\section{REFERENCES}

1. Charles M. Court-Brown, Stuart A. Aitken, Daren Forward, Robert V. O'Toole III. The Epidemiology of Fractures. In: Robert W. Bucholz, James D. Heckman, Charles M. Court-Brown, Paul Tornetta III, editors. Rockwood and Green's Fractures in Adults, $7^{\text {th }}$ edition. Wolters Kluwer/Lippincott Williams \& Wilkins; 2010. p.53-84.

2. Abrahamsen B, van Staa $T$, Ariely $R$, et al. Excess mortality following hip fracture: A systematic epidemiological review. Osteoporos Int 2009; 15:76778.

3. Islam S, Liu Q, Chines A, Helzner $\mathrm{E}$. Trend in incidence of osteoporosis-related fractures among 40 to 69-year-old women: Analysis of a large insurance claims database, 2000-2005. Menopause. 2009; 16(1):77-83.

4. Thakar C, Alsousou J, Hamilton TW, Willett K. The cost and consequences of proximal femoral fractures which require further surgery following initial fixation. J Bone Joint Surg Br. 2010; 92(12):1669-77.

5. Dhamangaonkar AC, Joshi D, Goregaonkar AB, Tawari $A A$. Proximal femoral locking plate versus dynamic hip screw for unstable intertrochanteric femoral fractures. J Orthop Surg (Hong Kong). 2013; 21 (3):31722.

6. Gupta RK, Sangwan K, Kamboj P, Punia SS, Walecha $P$. Unstable trochanteric fractures: The role of lateral wall reconstruction. Int Orthop 2010; 34(1):125-9. 
7. John C. Weinlein. Fractures and Dislocations of the Hip. In: Canele ST, Beaty JH, editors. Campbell's Operative Orthopaedics. $12^{\text {th }}$ edition. Mosby: Elsevier; 2013. p2725-75.

8. Babar I, Qureshi AR, Afsar SS. An experience of the treatment of unstable inter-trochanteric fractures with the AO/ASIF Proximal Femoral Nail. JPMI. 2011; 25(3):267-71

9. Parker MJ, Handoll HH. Gamma and other cephalocondylic intramedullary nails versus extramedullary implants for extracapsular hip fractures in adults. Cochrane Database Syst Rev. 2010 Sep 8; (9):CD000093.

10. Liu M, Yang Z, Pei F, Huang F, Chen S, Xiang Z. A metaanalysis of the Gamma nail and dynamic hip screw in treating peritrochanteric fractures. Int Orthop. 2010 Mar; 34(3):323-8.

11. Nizegorodcew T, Maccauro G, Tafuro L, Aulisa A. Trochanteric Stabilizing Plate in the treatment of unstable lateral fractures of the proximal femur. $J$ Bone Joint Surg Br 2004 vol. 86-B no. SUPP III 377384.

12. Babst R, Renner N, Biedermann M, Rosso R, Heberer $M$, Harder $F$, et al. Clinical results using the trochanter stabilizing plate (TSP): The modular extension of the dynamic hip screw (DHS) for internal fixation of selected unstable intertrochanteric fractures. J Orthop Trauma. 1998; 12(6):392-9.

13. Anisuddin Bhatti, Suresh Kumar, Azad A Shaikh, Jamali A R, Kashif Mehmood. Outcome of lateral stabilization of unstable inter trochanteric fractures with trochanteric stabilization plate as an adjunct to dynamic hip screw fixation. J Pak Orthop Assoc 2010; 22(2):98-107.
14. Shabir M, Inam M, Awan AS, Kamran F, Ahmad N. Mean tip-apex distance in lag screw cut-out after dynamic hip screw fixation of hip fracture. JAyub Med Coll 2018; 30(3):414-416.

15. Cho MR, Lee JH, Kwon JB, Do JS, Chae SB, Choi WK. The effect of positive medial cortical support in reduction of pertrochanteric fractures with posteromedial wall defect using a dynamic hip screw. ClinOrthop Surg. 2018; 10(3):292-298.

16. Sharma A, Sethi A, Sharma S. Comparative analysis of treatment of basicervical femur fractures in young adults with CCS, DHS and PFN. Rev Bras Ortop.2018; 53(6):783-787.

17. Kulkarni G S, Limaye R, Kulkarni M, Kulkarni S. Intertrochanteric fractures. Indian Journal of Orthopaedics 2006; 40(1):16-23.

18. Tucker A, Donnelly KJ, Rowan C, Mc Donald S, Foster AP.Is the Best Plate a Nail? A Review of $\mathbf{3 2 3 0}$ unstable intertrochanteric fractures of the proximal femur. $J$ Orthop Trauma 2018; 32(2):53-60.

19. Ashok S, Gavaskar, Naveen C, Tummala, Srinivasan P, Gopalan H, Kishthek B, Santhosh S. Helical blade or the integrated lag screw: A matched pair analysis of 100 patients with unstable trochanteric fractures. Journal of Orthopaedic Trauma. 2018; 32(6):274-277.

20. Kanis JA, Oden A, McCloskey EV, Johansson H, Wahl DA, Cooper C.A systemic review of hip fracture incidence and probability of fracture worldwide. Osteoporosis Int. 2012; 23(9):2239-2256.

\begin{tabular}{|c||c|c|c|}
\hline \multicolumn{3}{|c}{ AUTHORSHIP AND CONTRIBUTION DECLARATION } \\
\hline No. & \multicolumn{1}{|c|}{ Author(s) Full Name } & \multicolumn{1}{|c|}{ Contribution to the paper } & Author(s) Signature \\
\hline 1 & Muhammad Asif & Data collection, Compilation. \\
\hline 2 & Yaqoob ur Rehman & $\begin{array}{l}\text { Data and article collection for } \\
\text { references. } \\
\text { Results \& Discussion } \\
\text { compilation. }\end{array}$ \\
\hline
\end{tabular}

